\title{
PERANCANGAN PROTOTIPE BIOREAKTOR UNTUK PENGOLAHAN LANJUT LIMBAH CAIR PABRIK KELAPA SAWIT (LCPKS) SECARA AEROBIK
}

\author{
Bambang Trisakti, Jhon Almer S. Pasaribu, Tri Afrianty, T. Husaini, Irvan \\ Departemen Teknik Kimia, Fakultas Teknik, Universitas Sumatera Utara, \\ Jl. Almamater Kampus USU, Medan 20155, Indonesia \\ Email: b_trisakti@yahoo.com
}

\begin{abstract}
Abstrak
Pengolahan lanjut LCPKS biasanya dilakukan dengan menggunakan sistem lumpur aktif yang dilaksanakan pada suatu kolam terbuka. Sistem ini memerlukan oksigen terlarut cukup besar sehingga jika sistem aerasi kurang baik akan menyebabkan HRT menjadi besar. Selain itu terjadinya penyebaran bau busuk karena sistem yang digunakan adalah terbuka. Penelitian ini bertujuan untuk menghasilkan prototipe bioreaktor yang dapat digunakan untuk menggantikan sistem pengolahan di atas. Tangki Bioreaktor dibuat dari tabung plastik transparan yang dilengkapi oleh baffle dan pengaduk yang terbuat dari steinless steel. Selain itu, bioreaktor juga dilengkapi dengan motor pengaduk, sistem aerasi, dan unit penghilang bau. Prototipe yang dihasilkan memiliki tinggi $11,078 \mathrm{~cm}$ dan diameter 21,4 cm, volume operasional 9,2 liter, tinggi cairan dan baffle adalah $24,5 \mathrm{~cm}$. Bioreaktor dilengkapi dengan dua bilah pengaduk yakni turbin piringan horizontal yang posisinya 7,13 cm dari dasar tangki dan dayung 4-pendayung 4 yang posisinya 12,84 cm di atas bilah pertama. Prototipe bioreaktor telah lolos uji kebocoran dan jika dialiri udara dengan kecepatan konstan 0,5 $\mathrm{m} / \mathrm{s}$ maka nilai gas holdup (E) adalah 0,02. Penggunaan prototipe ini untuk pengolahan lanjut LCPKS menyebabkan nilai COD limbah turun dari $4.482 \mathrm{mg} / \mathrm{l}$ menjadi $3.096 \mathrm{mg} / \mathrm{l}$ setelah diproses selama 30 hari.
\end{abstract}

Kata Kunci : Lumpur aktif, Bioreaktor, LCPKS, dan COD

\begin{abstract}
LCPKS further processing is usually done by using activated sludge system is implemented in an open pond. This system requires a large enough dissolved oxygen so that if the system would lead to poor aeration then the HRT will be great. In addition to the spread of foul smell due to the system being used is open. This study aims to produce a prototype bioreactor that can be used to replace the above processing system. Bioreactor tank made of transparent plastic tube that comes by baffles and stirrer are made of stainless steel. In addition, the bioreactor is also equipped with a motor stirrer, aeration systems, and deodorizing unit. The resulting prototype has $11.078 \mathrm{~cm}$ high and $21.4 \mathrm{~cm}$ diameter, 9.2-liter operating volume, and fluid and baffle height is $24.5 \mathrm{~cm}$. Bioreactor equipped with two stirrer blade that is horizontal turbine disc type at $7.13 \mathrm{~cm}$ of the tank bottom and paddle 4-rowing at $12.84 \mathrm{~cm}$ above the first blade. Bioreactor prototype has passed the leakage test and if the air flowing in at a constant velocity $0.5 \mathrm{~m} / \mathrm{s}$ then the value of gas holdup $(\varepsilon)$ is 0.02. Used this prototype for further processing LCPKS cause COD value of waste fell from 4,482 $\mathrm{mg} / \mathrm{l}$ to 3,096 $\mathrm{mg} / \mathrm{l}$ for 30 days long processed.
\end{abstract}

Keywords: Activated Sludge, Bioreactor, POME, and COD

\section{Pendahuluan}

Konversi limbah cair pabrik kelapa sawit (LCPKS) menjadi biogas menggunakan digester anaerobik sudah banyak diteliti bahkan telah diaplikasikan secara komersial dibeberapa PKS di Indonesia dan Malaysia [1, 11]. Hal ini disebabkan pengolahan konvensioanal LCPKS yang menggunakan kolam terbuka (lagoon) ternyata melepaskan biogas $\left(\mathrm{CH}_{4}\right.$ dan $\left.\mathrm{CO}_{2}\right)$ ke atmosfir sebagai emisi gas rumah kaca (GRK) $[4,10]$.

Sayangnya, proses menggunakan digester anaerobik ini hanya mampu menurunkan kadar COD $\pm 80 \%$ [10]. Sehingga jika kadar COD awal LCPKS adalah $\pm 54.000 \mathrm{mg} / \mathrm{l}$ maka keluaran cair daripada digester anaerobik ini masih $\pm 10.800 \mathrm{mg} / \mathrm{l}$. Nilai COD ini tentunya masih sangat jauh dari nilai baku mutu COD agar dapat dilepaskan ke badan air yakni $500 \mathrm{mg} / \mathrm{l}[6]^{\circ}$

Oleh karena itu, untuk menurunkan nilai COD-nya, diperlukan pengolahan lanjut. Pengolahan konvensional adalah dengan menggunakan sistem lumpur aktif (activated sludge) yang dilaksanakan pada kolam terbuka [2, 9]. Sistem ini adalah pengolahan secara biologis dengan bantuan mikroorganisme aerobik. Selain nutrisi yang dikandung limbah, diperlukan pula oksigen terlarut yang cukup besar yakni $\pm 0,5 \mathrm{mg} / \mathrm{l}$. Oleh karenanya, pada sistem kolam terbuka diperlukan Hydraulic Retention Time (HRT) besar.

Pada tulisan ini akan dipaparkan hasil perancangan, pabrikasi, dan pengujian suatu prototipe bioreaktor aerobik, yang diharapkan 
dapat digunakan untuk pengolahan lanjut LCPKS secara aerobik.

\section{Teori}

Pabrik Kelapa Sawit (PKS) memiliki karakteristik limbah cair yang berbeda-beda tetapi pada umumnya mengandung padatan terlarut dan tersuspensi berupa koloid dan residu minyak dengan nilai biological oxygen demand (BOD) yang tinggi, berwarna kecoklatan, dan bersuhu tinggi, seperti yang disajikan pada Tabel $1[2,9]$.

Tabel 1. Karakteristik LCPKS

\begin{tabular}{|l|c|c|}
\hline \multicolumn{1}{|c|}{ Parameter } & Satuan & Kisaran \\
\hline $\begin{array}{l}\text { BOD (Biological } \\
\text { Oxygen Demand) }\end{array}$ & $\mathrm{mg} / \mathrm{l}$ & $20.000-30.000$ \\
\hline $\begin{array}{l}\text { COD (Chemical } \\
\text { Oxygen Demand) }\end{array}$ & $\mathrm{mg} / \mathrm{l}$ & $40.000-60.000$ \\
\hline $\begin{array}{l}\text { TSS (Total } \\
\text { Suspended Solid) }\end{array}$ & $\mathrm{mg} / \mathrm{l}$ & $15.000-40.000$ \\
\hline TS (Total Solid) & $\mathrm{mg} / \mathrm{l}$ & $30.000-70.000$ \\
\hline Minyak dan Lemak & $\mathrm{mg} / 1$ & $5.000-7.000$ \\
\hline NH3-N & $\mathrm{mg} / \mathrm{l}$ & $30-40$ \\
\hline Total N & $\mathrm{mg} / 1$ & $500-800$ \\
\hline Suhu & ${ }^{\circ} \mathrm{C}$ & $90-140$ \\
\hline $\mathrm{pH}$ & - & $4-5$ \\
\hline
\end{tabular}

Oleh karenanya, LCPKS tidak dapat dibuang langsung ke badan air (sungai/parit), karena akan sangat berbahaya bagi lingkungan. Saat ini, umumnya Instalasi Pengolahan Air Limbah (IPAL) PKS adalah berupa kolam-kolam terbuka (lagoon) dimana LCPKS akan diolah secara biologis agar nilai parameter pencemar dapat direduksi sampai lebih kecil atau sama dengan baku mutu, seperti yang disajikan pada Tabel 2 [6].

Tabel 2. Baku Mutu LCPKS keluaran IPAL

\begin{tabular}{|l|c|c|}
\hline Parameter & Satuan & Baku Mutu \\
\hline BOD & $\mathrm{mg} / \mathrm{l}$ & 250 \\
\hline $\mathrm{COD}$ & $\mathrm{mg} / \mathrm{l}$ & 500 \\
\hline $\mathrm{TSS}$ & $\mathrm{mg} / \mathrm{l}$ & 300 \\
\hline Minyak \& Lemak & $\mathrm{mg} / \mathrm{l}$ & 30 \\
\hline $\mathrm{NH}_{3}-\mathrm{N}$ & $\mathrm{mg} / \mathrm{l}$ & 20 \\
\hline $\mathrm{pH}$ & - & $6-9$ \\
\hline $\begin{array}{l}\text { Debit Limbah } \\
\text { Maksimum }\end{array}$ & $\begin{array}{c}\mathrm{m}^{3} / \mathrm{ton} \\
\mathrm{CPO}\end{array}$ & 6 \\
\hline
\end{tabular}

Selain memerlukan lahan yang luas (HRT \pm 97 hari), secara alami, limbah cair di dalam kolam akan melepaskan emisi gas rumah kaca yang berbahaya bagi lingkungan $[1,4,10]$. Gas-gas tersebut antara lain adalah campuran dari gas metan $\left(\mathrm{CH}_{4}\right)$ dan karbon dioksida $\left(\mathrm{CO}_{2}\right)$. Kedua gas ini sebenarnya adalah biogas yang dapat dimanfaatkan sebagai sumber energi $[4,10]$.

Pengolahan LCPKS menjadi biogas pada digester anaerobik, sebenarnya sudah banyak dilaporkan, bahkan sudah diaplikasikan pada skala komersial pada beberapa PKS di Indonesia dan Malaysia [1, 11]. Akan tetapi, proses ini hanya mampu meredukasi COD $\pm 80 \%$, sehingga keluaran cair (effluent) digester anaerobik, seperti yang disajikan pada Tabel 3 [4, 7, 10], masih jauh dari nilai parameter baku mutu.

Tabel 3. Komposisi Keluaran (effluent) Digester Anaerobic

\begin{tabular}{|l|c|c|}
\hline \multicolumn{1}{|c|}{ Parameter } & Satuan & Nilai \\
\hline TS (Total Solid) & $\mathrm{mg} / \mathrm{l}$ & 11,900 \\
\hline VS (Volatile Solid) & $\mathrm{mg} / \mathrm{l}$ & 7,500 \\
\hline $\begin{array}{l}\text { TSS (Total Suspended } \\
\text { Solid) }\end{array}$ & $\mathrm{mg} / \mathrm{l}$ & 2,570 \\
\hline $\begin{array}{l}\text { VSS (Volatile Suspended } \\
\text { Solid) }\end{array}$ & $\mathrm{mg} / \mathrm{l}$ & 2,200 \\
\hline $\begin{array}{l}\text { BOD (Biological Oxygen } \\
\text { Demand) }\end{array}$ & $\mathrm{mg} / \mathrm{l}$ & 3,050 \\
\hline $\begin{array}{l}\text { COD (Chemical Oxygen } \\
\text { Demand) }\end{array}$ & $\mathrm{mg} / \mathrm{l}$ & 8,600 \\
\hline $\mathrm{T}-\mathrm{N}$ & $\mathrm{mg} / \mathrm{l}$ & 490 \\
\hline $\mathrm{NH}{ }_{3}-\mathrm{N}$ & $\mathrm{mg} / \mathrm{l}$ & 65 \\
\hline $\mathrm{T}-\mathrm{P}$ & $\mathrm{mg} / \mathrm{l}$ & 110 \\
\hline $\mathrm{K}$ & $\mathrm{mg} / \mathrm{l}$ & 1,900 \\
\hline $\mathrm{Ca}$ & $\mathrm{mg} / \mathrm{l}$ & 23 \\
\hline $\mathrm{Mg}$ & $\mathrm{mg} / \mathrm{l}$ & 256 \\
\hline $\mathrm{Cd}$ & $\mathrm{mg} / \mathrm{l}$ & $<0.01$ \\
\hline $\mathrm{As}$ & $\mathrm{mg} / \mathrm{l}$ & $<0.01$ \\
\hline $\mathrm{Zn}$ & $\mathrm{mg} / \mathrm{l}$ & 0.61 \\
\hline $\mathrm{Cr}$ & $\mathrm{mg} / \mathrm{l}$ & 0.04 \\
\hline $\mathrm{Hg}$ & $\mathrm{mg} / \mathrm{l}$ & $<0.0005$ \\
\hline
\end{tabular}

Pengolahan lanjut LCPKS dengan proses lumpur aktif yang biasanya dilakukan pada kolam terbuka diupayakan untuk dilaksanakan pada suatu sistem bioreaktor aerobik.

\section{Bioreaktor}

Bioreaktor yang didalam reaktor tangki berpengaduk dengan metode aerasi, selain sistem pengadukan dan pemasokan oksigen, juga dilengkapi perlengkapan dasar bioreaktor yaitu sistem pengendalian busa, pengendalian suhu, dan pengendalian $\mathrm{pH}$. Tujuan dipakainya sistem agitasi adalah untuk membantu penyebaran gas dalam effluent sebagai gelembung-gelembung udara halus yang dibutuhkan mikroorganisme, layaknya oksigen untuk proses lumpur aktif dalam pengolahan limbah. Jenis bilah yang sering digunakan untuk keperluan ini, yaitu : 
1. Jenis Propeler (baling-baling)

2. Jenis Paddle (dayung), dan

3. Jenis Turbin

Jenis-jenis bilah yang digunakan pada bioreaktor akan menghasilkan pola aliran yang berbeda-beda, dimana bergantung dari sifat-sifat fluida, geometri tangki, jenis baffle (sekat) dan jenis bilah itu sendiri [3]. Pola aliran yang dihasilkan akibat pemilihan bilah berbeda disajikan pada Gambar 1.

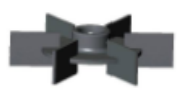

(a)
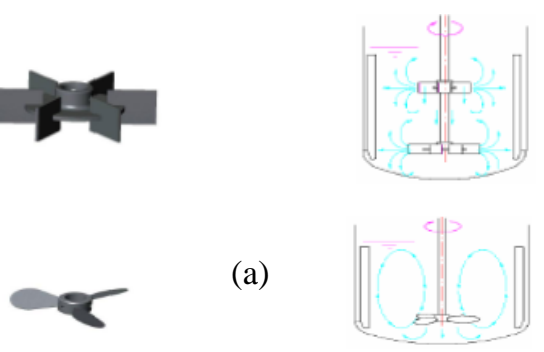

(b)

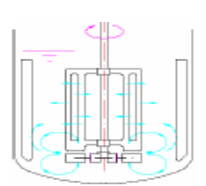

(c)

Gambar 1. Jenis bilah dan Pola Aliran; a) Flat blade disk turbine, b) Large pitch blade impeller, c) Maxblend.

\section{Metode Penelitian}

Penelitian ini dilakukan di Laboratorium Pilot Plant Pembangkit Listrik Tenaga Biogas, Pusdiklat LPPM, Universitas Sumatera Utara. Bahan yang digunakan adalah effluent LCPKS yang berasal dari bioreaktor anaerobik pengolahan biogas. Sedangkan peralatan yang digunakan adalah pompa, agitator, bioreaktor, dan aerator. Peralatan analisis yang digunakan adalah furnace, cawan, neraca analitik, erlenmeyer, dan buret. Tahapan-tahapan penelitian adalah pendisainan bioreaktor aerobik secara literatur, pabrikasi, pembuatan bioreaktor secara mekanis, komisioning, yaitu melakukan test run dari semua peralatan dan sekaligus melakukan kalibrasi terhadap peralatan ataupun aksesoris, pengujian sampel dengan parameter karakterisasi meliputi COD (Chemical Oxygen Demand) dan pengukuran gas holdups.

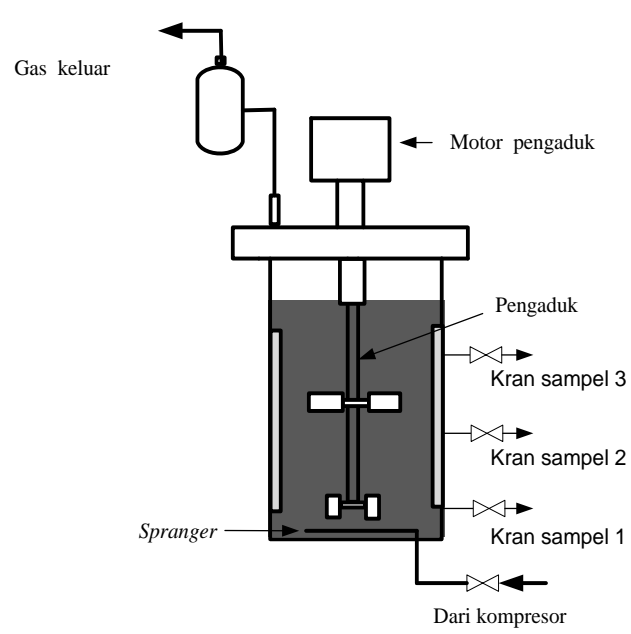

Gambar 2. Skema Reaktor Aerobik

\section{Hasil dan Pembahasan}

\section{Perancangan Bioreaktor}

Bioreaktor merupakan peralatan utama dalam penelitian ini. Perancangan bioreaktor aerobik harus memperhatikan tiga hal, yaitu :
a. Volume reaktor
b. Kebutuhan oksigen, dan
c. Kebutuhan tenaga minimal untuk pengadukan yang memadai.

Perhitungan perancangan bioreaktor berpengaduk berdasarkan literatur yang tersedia dimana dilengkapi dengan bilah jenis paddle berdayung empat dan turbin piringan horizontal serta menggunakan baffle.

\section{a. Perhitungan volume reaktor}

Volume (V), tinggi (L), tinggi baffle (H), dan diameter (D) reaktor dihiting menggunakan persamaan berikut $[5,12]$ :

$$
\begin{aligned}
V & =\frac{\pi}{4} D^{2} \cdot L \\
L & =H+\frac{H}{5} \\
H & =k \cdot D \\
L & =k \cdot D+\frac{k \cdot D}{5}=\frac{6 \cdot k \cdot D}{5} \\
V= & \frac{\pi}{4} D^{2} \cdot \frac{6 \cdot k \cdot D}{5}=\frac{6 \pi k}{20} D^{3} \\
D & =\sqrt[3]{\frac{20}{6 \pi k} V}
\end{aligned}
$$

Dengan mengambil nilai $\mathrm{k}=1,2$, maka ukuran prototipe bioreaktor aerobik adalah:

$$
\begin{aligned}
& D=21,4 \mathrm{~cm} \\
& H=k \cdot D=25,68 \mathrm{~cm}
\end{aligned}
$$


$\mathrm{L}=30,816 \mathrm{~cm}$

$\mathrm{V}=11.078,308 \mathrm{~cm}^{3}=11,078$ liter

$\mathrm{V}_{1}=9.231,92 \mathrm{~cm}^{3}=9,2$ liter

\section{Keterangan:}

$\mathrm{D}=$ Diameter bioreaktor

$\mathrm{L}=$ Tinggi bioreaktor

$\mathrm{H}=$ Tinggi cairan dalam bioreaktor

$\mathrm{k}$ = Perbandingan diameter dengan tinggi cairan

$\mathrm{V}=$ Volume bioreaktor total

$\mathrm{V}_{1}=$ Volume cairan di dalam bioreaktor

\section{b. Perhitungan ukuran dan posisi bilah}

Kinerja bioreaktor aerobik berpengaduk ditentukan pula oleh ukuran dan jenis bilah pengaduk yang digunakan. Bioreaktor aerobik ini menggunakan bilah pengaduk jenis turbin piringan horizontal yang berada sekitar $7,13 \mathrm{~cm}$ dari dasar bioreaktor. Sedangkan bilah kedua adalah jenis paddle berdayung 4 yang dipasang $12,84 \mathrm{~cm}$ di atas bilah pertama. Ukuran dan posisi kedua-dua bilah dihitung berdasarkan persamaan yang disajikan pada Gambar $3[3,5]$.

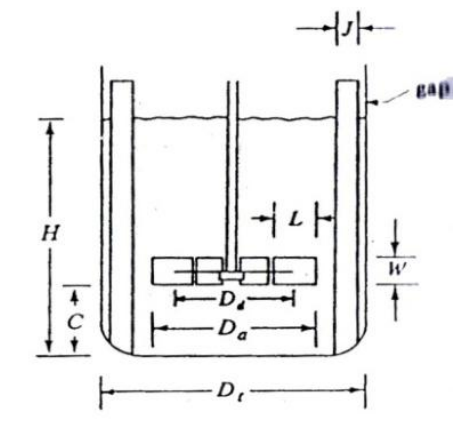

$$
\begin{array}{rlrl}
\frac{D_{a}}{D_{t}} & =0,3-0,5 & \frac{L}{D_{a}} & =\frac{1}{4} \\
\frac{W}{D_{a}} & =\frac{1}{5} & \frac{J}{D_{t}} & =\frac{1}{12} \\
\frac{D_{d}}{D_{a}} & =\frac{2}{5} &
\end{array}
$$

\section{Gambar 3. Ukuran dan Posisi Bilah Pengaduk}

Berdasarkan persamaan di atas dapat ditentukan ukuran dan posisi bilah pengaduk, yakni:

$$
\begin{array}{ll}
\mathrm{D}_{\mathrm{a}}=8,56 \mathrm{~cm} & \mathrm{~L}=2,14 \mathrm{~cm} \\
\mathrm{~W}=1,712 \mathrm{~cm} & \mathrm{~J}=1,78 \mathrm{~cm} \\
\mathrm{D}_{\mathrm{d}}=5,71 \mathrm{~cm} & \mathrm{C}=\mathrm{D} / 3=7,13 \mathrm{~cm}
\end{array}
$$

Hasil disain prototipe bioreaktor dan jenis bilahnya disajikan pada Gambar 4, sedangkan spesifikasi lengkapnya disajiakan pada Tabel 4.
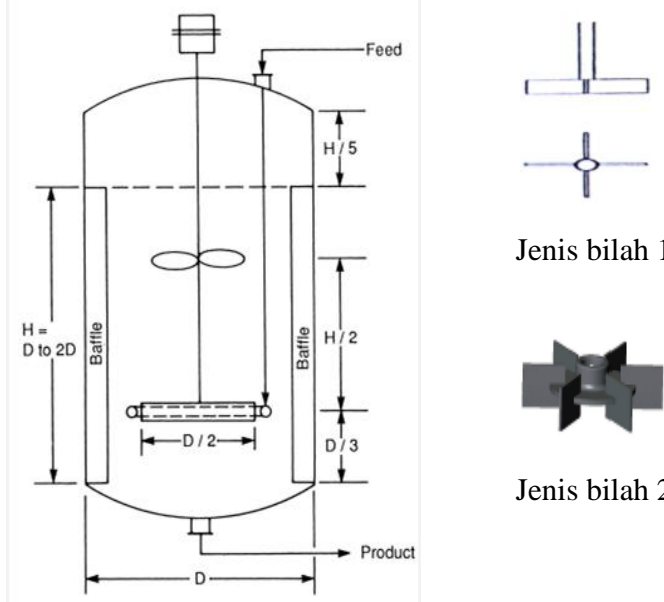

Jenis bilah 1

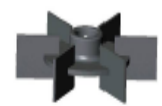

Jenis bilah 2

Gambar 4. Disain Teknikal Bioreaktor dan Jenis serta Posisi Bilah Pengaduk

Tabel 4. Spesifikasi Prototipe Bioreaktor

\begin{tabular}{|ll|}
\hline Tangki & \\
Diameter & $21,4 \mathrm{~cm}$ \\
Tinggi total & $30,82 \mathrm{~cm}$ \\
Tinggi baffle & $25,68 \mathrm{~cm}$ \\
Volume reaktor & 9,2 liter \\
\hline Motor & \\
Daya & $80 \mathrm{Watt}$ \\
Voltase & AC $110 \mathrm{~V}$ \\
Frekuensi & $50 / 60 \mathrm{~Hz}$ \\
W & $30 \mathrm{rpm}$ \\
Merek & $A S$ ONE \\
\hline Pengaduk & \\
Jumlah bilah & 2 \\
Posisi bilah 1 & $7,13 \mathrm{~cm}$ dari dasar tangki \\
Posisi bilah 2 & $12,84 \mathrm{~cm}$ di atas bilah 1 \\
Jenis bilah 1 & Paddle berdayung 4 \\
Jenis bilah 2 & Turbin Piringan Horizontal \\
Diameter bilah & $8,56 \mathrm{~cm}$ \\
Lebar bilah & $1,712 \mathrm{~cm}$ \\
\hline
\end{tabular}

\section{$\underline{\text { Pabrikasi Bioreaktor }}$}

Tangki bioreaktor dipabrikasi dengan menggunakan tabung plastik transparan berketebalan $4 \mathrm{~mm}$ dan dilengkapi dengan baffle. Pada bagian atas tertutup rapat, dipasang pipa yang dihubungkan dengan tabung berisi air dengan fungsi menyerap bau yang dihasilkan selama penelitian dan dipasang motor untuk menggerakkan pengaduk. Sedangkan pengaduk dan baffle terbuat dari stainless steell. Dokumentasi pabrikasi protipe bioreaktor adalah seperti yang disajikan pada Gambar 5 sedangkan hasilnya disajikan pada Gambar 6. 


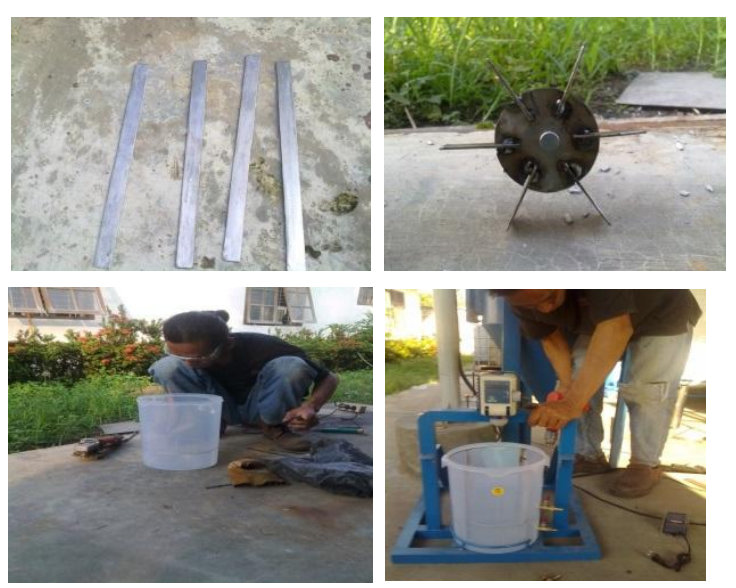

Gambar 5. Pabrikasi Bioreaktor dan Pengaduk

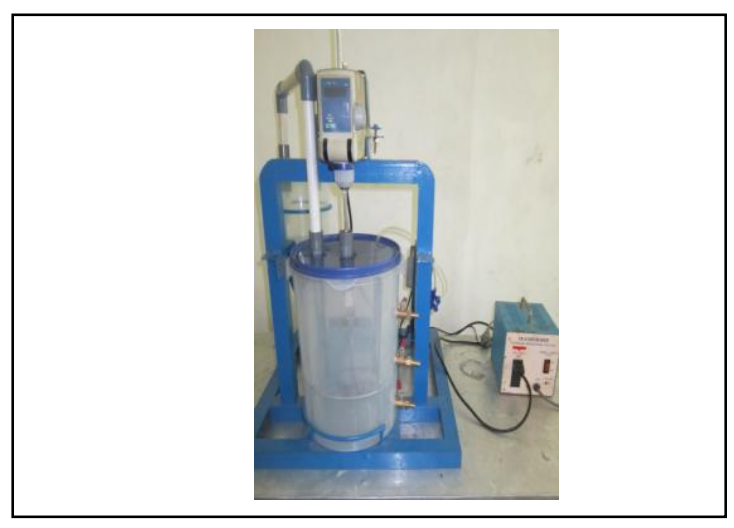

Gambar 6. Bioreaktor dan Pengaduk Setelah Pabrikasi

\section{Pengujian Bioreaktor}

Pengujian bioreaktor adalah meliputi pengujian kebocoran bioreaktor yang dilakukan setelah proses pabrikasi berlangsung, kemudian dilanjutkan dengan pengujian kinerja bioreaktor aerobik. Parameter yang diukur adalah pengukuran gas holdups, dan perubahan nilai COD (chemical oxygen demand) dari LCPKS keluaran (effluent) fermentor biogas yang diaerasi dan diaduk selama \pm 30 hari. Titik pengambilan sampel dilakukan dari tiga kran yang masing-masing dipasang pada bagian bawah, tengah, dan atas bioreaktor. Pengambilan sampel dilakukan selang dua hari sekali, sebanyak $20 \mathrm{ml}$ pada setiap krannya.

\section{Pengukuran Gas Holdups}

Gas holdups merupakan volume gas yang berada atau tertinggal di dalam fase cair pada sistem cair-gas. Pengetahuan tentang gas holdups penting dalam menetukan kadar perpindahan massa dan keberhasilan pencampuran dua fase cair-gas. Nilai gas holdups dihitung berdasarkan persamaan [13]:

$$
\varepsilon=\frac{h_{1}-h_{0}}{h_{0}}
$$

Dimana:

$$
\begin{aligned}
& \varepsilon=\text { gas holdups } \\
& \mathrm{h}_{\mathrm{o}}=\text { tinggi cairan awal } \\
& \mathrm{h}_{1}=\text { tinggi cairan akhir }
\end{aligned}
$$

Gambar 7 menunjukkan adanya kenaikan tinggi cairan dalam bioreaktor akibat sistem aerasi, pengaliran udara ke dalam bioreaktor. Kecepatan udara yang masuk selama penelitian dijaga konstan $0,5 \mathrm{~m} / \mathrm{s}$ dengan $\mathrm{h}_{\mathrm{o}}=24,5 \mathrm{~cm}$ dan diperoleh $\mathrm{h}_{1}=25$ $\mathrm{cm}$, maka gas holdups $(\varepsilon)=0,02$.

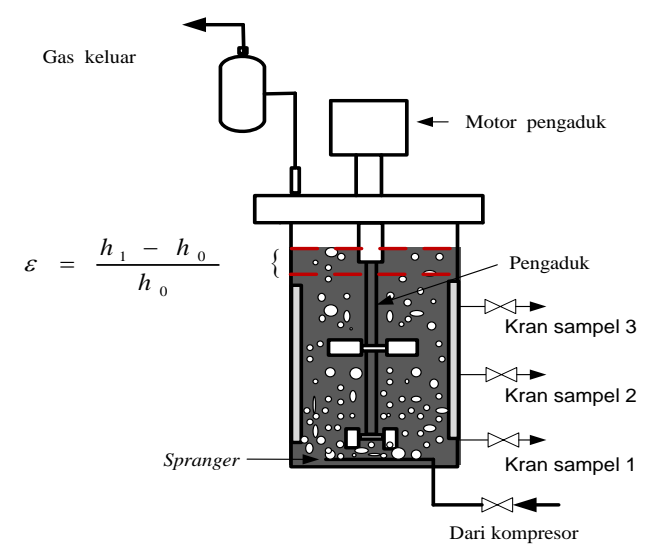

Gambar 7. Kenaikan Tinggi Cairan Akibat Gas Holdups.

\section{Perubahan Nilai COD Effluent}

Nilai COD adalah jumlah kebutuhan oksigen yang ekivalen dengan kandungan bahan organik pada air limbah (effluent) yang dapat dioksidasi oleh oksidan kimia yang kuat. Oksidasi bahan organik menghasilkan $\mathrm{CO}_{2}$ dan $\mathrm{H}_{2} \mathrm{O}$. Nilai $\mathrm{COD}$ akan semakin menurun akibat proses oksidasi dan sebagian bahan organik dikonversi menjadi sel baru [8].

Gambar 8 menunjukkan kadar COD pada effluent menurun dari $4.482 \mathrm{mg} / \mathrm{l}$ menjadi 3.096 $\mathrm{mg} / \mathrm{l}$ setelah limbah diolah selama 30 hari. Walaupun nilai COD akhir masih diatas nilai baku, namun dengan adanya perubahan nilai COD pada limbah yang diproses menunjukkan adanya aktifitas mikroorganisme dan degradasi effluent telahpun terjadi.

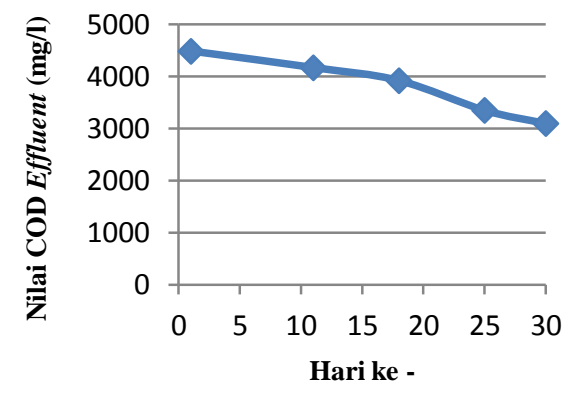

Gambar 8. Penurunan Nilai COD Effluent 


\section{Kesimpulan}

1. Disain, pabrikasi, dan instalasi prototipe bioreaktor aerobik berdasarkan literatur telah berhasil dilakukan. Tangki bioreaktor dibuat dari tabung plastik transparan, sedangkan baffle dan pengaduk terbuat dari stainless steell.

2. Tinggi dan diameter tangki dari protipe bioreaktor aerobik adalah masing-masing $11,078 \mathrm{~cm}$ dan $21,4 \mathrm{~cm}$. Volume operasional bioreaktor adalah 9,2 liter, dengan tinggi cairan dan tinggi baffle adalah $24,5 \mathrm{~cm}$. Bioreaktor dilengkapi dengan dua bilah pengaduk yakni turbin piringan horizontal yang posisinya 7,13 $\mathrm{cm}$ dari dasar tangki dan dayung 4-pendayung yang posisinya $12,84 \mathrm{~cm}$ di atas bilah pertama.

3. Nilai gas holdups $(\varepsilon)$ jika kecepatan udara dijaga konstan sebesar $0,5 \mathrm{~m} / \mathrm{s}$ adalah sebesar 0,02 .

4. Pengolahan lanjut LCPKS dengan menggunakan protipe bioreaktor aerobik yang dihasilkan menyebabkan terjadinya penurunan nilai COD dari $4.482 \mathrm{mg} / \mathrm{l}$ menjadi $3.096 \mathrm{mg} / \mathrm{l}$ setelah diproses selama 30 hari.

5. Kecepatan udara maksimum yang dapat digunakan adalah $0,5 \mathrm{~m} / \mathrm{s}$ sehingga kenaikan gas holdups sangat kecil.. Hal ini disebabkan oleh panjang spranger maksimum yang tersedia dipasaran relatif kecil yakni $\pm 5 \mathrm{~cm}$.

\section{Ucapan Terimakasih}

Penulis mengucapkan terimakasih kepada Direktur Jendral Pendidikan Tinggi Republik Indonesia yang telah mendanai penelitian ini melalui Hibah Kompetitif Penelitian Unggulan Strategis Nasional No. 169/SP2H/PL/Dit.Litabmas /III/2012 Tanggal 7 Maret 2012.

\section{Pustaka}

[1] Anwar A., Rumana G., dan Zularisam A.W, Bioenergy from anaerobic degradation of lipids in palm oil mill effluent, Review Environment Science Biotechnology, 10(2011), p. 353-376.

[2] Departemen Pertanian, "Pedoman Pengelolaan Limbah Industri Kelapa Sawit", Ditjen PPHP, Jakarta, 2006, p. 15-18.

[3] Geankoplis, C.J, Transport Process and Separation Process Principles, 4th Edition, Prentice Hall, New Jersey, 1983.

[4] Irvan, Bambang Trisakti, V. Wongistani, Y. Tomiuchi, Methane Emission from Digestion of Palm Oil Mill Effluent (POME) in a Thermophilic Anaerobic Reactor, International J. of Sci. and Eng., 3:1(2012). 32-35.

[5] Jagani et al, An Overview of Fermenter and the Design Considerations to Enhance Its
Productivity, Pharmacologyonline, 1(2010), p. 261-301.

[6] Kementerian Lingkungan Hidup Republik Indonesia, Keputusan Menteri Lingkungan Hidup Nomor: KEP 51/MEN KLH/10/1995 Tentang: Baku Mutu Limbah Cair bagi Kegiatan Industri, 1995.

[7] Kementerian Lingkungan Hidup Republik Indonesia, Keputusan Menteri Lingkungan Hidup Nomor 29 Tahun 2003. Tentang. Pedoman, Syarat, dan Tata Cara Perizinan Pemanfaatan Air Limbah Industri Minyak Sawit Pada Tanah di Perkebunan Kelapa Sawit, 2003.

[8] Romli, M, Suprihatin dan Dinna Sulida, Penentuan Nilai Parameter Kinetika Lumpur Aktif untuk Pengolahan Air Lindi Sampah (Leachate), Jur.Tek. Ind. Pert. 14:2(2010), p. 55-26.

[9] Rupani, P.F., R.P. Singh, M.H. Ibrahim, \& N. Esa, Review of Current Palm Oil Mill Effluent (POME) Treatment Methods: Vermicomposting as a Sustainable Practice, World Applied Sciences Journal. 11:1(2010). p. 70-81.

[10] Tomiuchi, Y., Bambang Trisakti, Irvan, Development of Palm Oil Mill Effluent (POME) Methane Fermentation System. The 4th IWA-ASPIRE, Conference \& Exhibition, Tokyo. Japan. 2011.

[11] Tong, S.L., \& A.B. Jaafar, POME Biogas Capture, Upgrading, and Utilization. Proceedings of the PIPOC 2005 International Palm Oil Congress (Chemistry and Technology), 2005, p. 328-336.

[12] Walas, Stanley M. Chemical process equipment, Butterworth-Heinemann, Washington. 1988.

[13] Zuhrina, Model Matematik Gas Hold Up di dalam Tangki Berpengaduk, USU digital Library, Medan, 2004. 